\title{
Frailty at the beginning of dialysis; is it a prognostic factor?
}

\author{
Santiago Silva ${ }^{1 * \oplus}$, Cristina Milano $^{1 \oplus}$, Gonzalo García $^{1 \oplus}{ }^{\text {Anabel Abib }}{ }^{1 \oplus}$, Carlos Díaz $^{1 \oplus}$, Gustavo Laham $^{1 \oplus}$
}

\begin{abstract}
Introduction: Frailty (F) refers to the cumulative organic damage caused by aging, as a consequence of a diminished physiological reserve. Frailty's prevalence is $73 \%$ in dialysis.

Objectives: Our aim was to identify the prevalence of $\mathrm{F}$ in patients starting hemodialysis (HD) or hemodiafiltration online (HDF) treatment to asses change in frailty during a six-month period of dialysis.

Patients and Methods: This prospective cohort study evaluated 67 incident patient starting-HD or HDF at one year, with a follow-up period of at least six months. The frailty was assessed by the Fried frailty method. According to this test, we divided the population in two groups: Pre-frail (0-2) and frail (3-5).

Results: Mean age was 64 years, $64 \%$ were male and $92 \%$ were treated with HD. A total of $35.8 \%$ of the patients were admitted to dialysis with a prosthetic or native fistula. The prevalence of $\mathrm{F}$ at the beginning of dialysis was $65.7 \%$. The mean value of Charlson index $(\mathrm{CHI})$ was $5.2 \pm 2$. There was a significant correlation between $\mathrm{CHI}$ and frailty test $(P<0.0001)$. Basal F score $(\mathrm{n}=67)$ improved after 6 month $(\mathrm{n}=52)$ : $3(2-4)$ versus1 $(1-2)(P<0.0001)$. Hematocrit $(28$ versus $32 \% P=0.05)$ and calcium levels $(8.6$ and $8.9 \mathrm{mg} / \mathrm{dL}, P<0.002)$ also increased after sixth-month. Global mortality was $7.5 \%$. In the multivariate analysis $\mathrm{CHI}(P<0.001)$ and albumin $(P=0.003)$ were frailty predictors. Conclusion: The prevalence of $\mathrm{F}$ in patients who start dialysis therapy is high. There was an improvement in $\mathrm{F}$ score after six-month of dialysis treatment. Patients with higher $\mathrm{F}$ score had higher mortality with higher $\mathrm{CHI}$.

Keywords: Dialysis, Sarcopenia, End-stage chronic renal disease

Citation: Silva S, Milano C, García G, Abib A, Díaz C, Laham G. Frailty at the beginning of dialysis; is it a prognostic factor? J Renal Endocrinol. 2021;7:e13. doi: 10.34172/jre.2021.13.

Copyright $(02021$ The Author(s); Published by Nickan Research Institute. This is an open-access article distributed under the terms of the Creative Commons Attribution License (http://creativecommons.org/licenses/by/4.0), which permits unrestricted use, distribution, and reproduction in any medium, provided the original work is properly cited.
\end{abstract}

\section{Introduction}

Historically, knowledge concerning aging was established upon the different biological mechanisms that lead to it, casting aside other matters unrelated to biology such as the psychosocial sphere (1). Following this new approach two principal syndromes where described, disability and comorbidity, which are now known to modify significantly quality of life (1). Disability in senile population was explained exclusively as a consequence of the underlying disease, without finding a physiopathological mechanism that accounted for it, in the absence of an established disease or its relationship with the process of aging itself (1). For this reason, over the past ten years, a new term has emerged, conceptualizing a new characteristic or phenotype, called frailty (1). This new phenotype or frailty syndrome, was first embraced by geriatricians to describe cumulative damage in multiple organic systems, produced by the process of aging itself (1-4). This leads to a state of diminished physiological reserve and tolerance to stressful insults, both internal and external (1-4). Therefore, frailty syndrome is defined as the cumulative damage of multiple organs and systems secondary to the mere process of aging, which results in a diminished physiological reserve (30\%) leading to an inadequate tolerance to internal and external insults (1-9). Woods et al describe four main risk factors for the development of frailty: physiological, comorbidity, socio-demographic and physiological (10). Frailty syndrome in chronic kidney disease (CKD) patients, without the need of renal replacement therapies (RRTs), account for the physiological dysfunction secondary to organic aging among other comorbidities $(2,11)$ Furthermore, patients who require RRT, other factors such as uremic syndrome and pro inflammatory states are added alongside conditions characteristic to hemodialysis (HD) (vascular access type, dialysis dose (Kt/V), anemia, bone mineral metabolism etc.) $(2,10)$. This syndrome affects a number of physiological areas such as the cognitive, emotional, nutritional, functional, strength, equilibrium, mobility and sleep. Moreover, it also has an impact in social aspects. This leads to the development of different diagnostic scores, to prevent and improve outcomes in patients suffering from frailty, which are now a new area of investigation (1). Overall, the Fried Frail test, is the most tested and applied, using five

Received: 23 January 2021, Accepted: 17 April 2021, ePublished: 18 May 2021

${ }^{1}$ Department of Internal Medicine, Neprhology Section, Centro de Educación Medica e Investigaciones Clinícas (CEMIC), Buenos Aires, Argentina.

*Corresponding Author: Santiago Silva, Email: sdst1986@gmail.com, sasilva @cemic.edu.ar 
Implication for health policy/practice/research/ medical education

Frail is an undervalued condition associated with great mortality on dialysis. A lot of studies evaluated frail in cross sectional analysis. We studied incident patients admitted to dialysis. We assessed the frailty prevalence of patients starting hemodialysis or hemodiafiltration and followed these patients prospectively for 6 months. To our knowledge, there is a lack of prospective studies in this area.

different variables to score a patients as non-frail (0), pre frail (score 1-2) or frail $(>3)(1,2,5,12-14)$. The prevalence of $\mathrm{F}$ accounts for $7 \%$ to $12 \%$ of general population and CKD at early stages and the incidence stands between $7 \%$ and $15 \%$, accounting for different ethnic groups and methods applied to quantify the frailty $(1,2)$. Frailty in population over forty years or older, varies between 42 and $73 \%$ with a frailty risk being 4 or 5 times greater than general population (2).

\section{Objectives}

Our aim was to identify the prevalence of frailty in patients starting HD or hemodiafiltration online (HDF) treatment. To asses change in frailty during a six-month period of dialysis

\section{Patients and Methods \\ Study design}

The study was designed as a single-centered prospective cohort study evaluating 67 incident patients starting HD or HDF between December 2017 and December 2018 with a follow up period of at least six months.

\section{Inclusion criteria}

- Incident patients (>18 years) starting HD or online high volume $\mathrm{HDF}$.

\section{Exclusion criteria}

- Patients treated with other forms of RRT (peritoneal dialysis or kidney transplant)

- Patients denial to perform the frailty test

\section{Variables}

The quantitative and qualitative variables for each patient where obtained from the EUCLID (European Clinical Database) database, an online program for data recollection of patients admitted for chronic RRT of Fresenius dialysis centers. Demographic data such as age, gender, cause of renal insufficiency, comorbidities, cardiovascular disease (considered as coronary artery disease, peripheral artery disease or the presence of aortic aneurysm), Charlson index (CHI) adjusted by age and validated for dialysis, RRT modality (HD or HDF), type of vascular access at entry (graft or native fistula or catheter, either permanent or transient). The weight taken into account was measured with BCM (Body Composition Monitor) after two weeks of treatment trying to account for the possible bias of fluid overweight or malnutrition. Blood sample analysis [albumin, creatinine, urea, PCR, ferritin, ferremia, transferrin, transferrin saturation percentage, hematocrit, calcium, phosphorus, intact parathyroid hormone (iPTH) and vitamin $\mathrm{D}$ were measured at the beginning and after six months of treatment.

\section{Fragility measurement}

Frailty was measured by the Fried Frail method which considers five physical variables (Table 1 ).

The test was first performed in the examination room before the first dialysis session and at month six. According to the obtained score the study population was divided into two groups:

1. Pre-frail: 0 to 2 points

2. Frail: 3 to 5 points

Non-frail patients were included in the pre-frail group to facilitate the statistical analysis at baseline due to the small number of patients ( 2 non-frail patients younger than 24 years).

\section{Ethical issues}

The research followed the tenets of the Declaration of Helsinki. The Ethics Committee of CEMIC University Institute of Medical Sciences approved this study. Accordingly, written informed consent was taken from all participants before any intervention.

\section{Statistical analysis}

The qualitative variables are described as percentages; the quantitative variables are expressed in means and medians with their standard deviation (SD) or interquartile range (IQR) as appropriate. Frailty was considered as a quantitative discrete variable for significance analysis with a minimum score of 0 and a maximum score of 5 points, distributed in two groups according to the score, pre-frail (0-2 points) and frail (3-5 points). This was considered at enrolment and at month six. The descriptive variables considered for each group where included according to clinical criteria and literature review, considering mortality and morbidity predictors in patients with RRT. Adjusted risk indices and confidence intervals of $95 \%$ (IC of $95 \%$ ) with a $P$ value $<0.05$ were used to establish statistical significance. For the analysis of comparison of continuous quantitative variables between admission and sixth month for the two groups, the Wilcoxon nonparametric test was used.

\section{Results}

A total of 67 patients initiated RRT. At month six, 52 patients $(77.6 \%)$ completed the study. Five patients died (7.5\%), four were transferred to other dialysis center (6\%), one patient recovered renal function and five (7.5\%) 
Table 1. Frailty test according to Fried frail (Cardiovascular Heart Study)

\begin{tabular}{|c|c|c|c|c|}
\hline \multirow{2}{*}{ Component } & \multirow{2}{*}{\multicolumn{2}{|c|}{ Physical Method }} & \multicolumn{2}{|c|}{ Score } \\
\hline & & & Yes & No \\
\hline Low weight & \multicolumn{2}{|c|}{$\begin{array}{l}\text { Unintentional weight loss } \geq 4.5 \mathrm{~kg} \text { in the } \\
\text { past year. }\end{array}$} & 1 & 0 \\
\hline Exhaustion & \multicolumn{2}{|c|}{$\begin{array}{l}\text { According to CES-D } 2 \text { parameters: } \\
\text { How often did you feel exhausted? } \\
\text { 0. Rarely or not (less than } 1 \mathrm{~d}) \text {, } \\
\text { 1. With certain frequency }(1-2 \mathrm{~d}) \text {, } \\
\text { 2. Moderate frequency }(3-4 \mathrm{~d}) \\
\text { 3. Most of the time. } \\
\text { 2-3 in the score, it is positive. }\end{array}$} & 1 & 0 \\
\hline $\begin{array}{l}\text { Physical } \\
\text { Activity }\end{array}$ & \multicolumn{2}{|c|}{$\begin{array}{l}\text { Short version of the Minnesota Leisure } \\
\text { Time Activity questionnaire 2011,* } \\
\text { stratified by sex: } \\
<383 \mathrm{kcal} / \mathrm{wk} \text { men } \\
<270 \mathrm{kcal} / \mathrm{wk} \text { women }\end{array}$} & 1 & 0 \\
\hline \multirow{3}{*}{$\begin{array}{l}\text { Walking } \\
\text { time }\end{array}$} & \multicolumn{2}{|c|}{$\begin{array}{l}\text { Based on a } 4.5 \mathrm{~m} \text { walking distance; } \\
\text { stratified by sex and height. }\end{array}$} & \multirow{3}{*}{1} & \multirow{3}{*}{0} \\
\hline & $\begin{array}{l}\text { Men } \\
\text { Height: } \\
\leq 173 \mathrm{~cm} \\
>173 \mathrm{~cm}\end{array}$ & $\begin{array}{l}\text { walking time } \\
\qquad 7 \mathrm{~s} \\
\geq 6 \mathrm{~s}\end{array}$ & & \\
\hline & $\begin{array}{l}\text { Women } \\
\text { Height } \\
\leq 159 \mathrm{~cm} \\
>159 \mathrm{~cm}\end{array}$ & $\begin{array}{l}\geq 7 \mathrm{~s} \\
\geq 6 \mathrm{~s}\end{array}$ & & \\
\hline \multirow[t]{2}{*}{$\begin{array}{l}\text { Grip } \\
\text { strength }\end{array}$} & $\begin{array}{l}\text { By men/womer } \\
\text { Men } \\
\text { BMl } \\
\leq 24 \mathrm{~kg} / \mathrm{m}^{2} \\
24.1-26 \mathrm{~kg} / \mathrm{m}^{2} \\
26.1-28 \mathrm{~kg} / \mathrm{m}^{2} \\
>28 \mathrm{~kg} / \mathrm{m}^{2}\end{array}$ & $\begin{array}{l}\text { Al: } \\
\begin{aligned} \text { Dynamometer** } \\
$\[ 29 \mathrm{~kg} \]$ \\
\leq 30 \mathrm{~kg} \\
\leq 31 \mathrm{~kg} \\
\leq 32 \mathrm{~kg}\end{aligned}\end{array}$ & \multirow[t]{2}{*}{1} & \multirow[t]{2}{*}{0} \\
\hline & $\begin{array}{l}\text { Women: } \\
\leq 23 \mathrm{~kg} / \mathrm{m}^{2} \\
23.1-26 \mathrm{~kg} / \mathrm{m}^{2} \\
26.1-29 \mathrm{~kg} / \mathrm{m}^{2} \\
>29 \mathrm{~kg} / \mathrm{m}^{2}\end{array}$ & $\begin{array}{l}\leq 17 \mathrm{~kg} \\
\leq 17.3 \mathrm{~kg} \\
\leq 18 \mathrm{~kg} \\
\leq 21 \mathrm{~kg}\end{array}$ & & \\
\hline Results & $\begin{array}{l}\text { 0: No frail } \\
\text { 1-2: Pre Frail } \\
3 \text {-5: Frail }\end{array}$ & & & \\
\hline
\end{tabular}

Modified from: Johansen et al. ${ }^{4}$

CESD-2: Epidemiological Center for Depression Studies, BMI: Body Mass Index, MET: unit of measure for metabolic index defined as the amount of heat emitted by a person at rest per square meter of skin equivalent to 50 $\mathrm{kcal} / \mathrm{h} / \mathrm{m}^{2}$

*Calculation by METS (resting metabolic unit) for each physical activity with the formula: kcal/week: METS $\times$ KG $\times$ Time in hours $\times$ days a week of the activity.

The activities carried out 3 months prior to admission to hemodialysis were considered, ruling out baseline activities (dressing, personal hygiene, sleeping, physiological functions) and taking into account those that imply moderate light intensity (1-1.5 METS) (1.6-3 METS). and great intensity (more than 6 METS)

** Instrument to measure force, based on the deformation capacity of elastic bodies.

received a kidney transplant (Figure 1).

Mean age was of $67 \pm 17$ years, 43 (64\%) were male. The follow-up period since RRT until end of study, death, renal transplant or transfer to other dialysis facility was 5.9 months (5.7-6.4). Considering patients with two or more renal risk factor (being hypertension the most prevalent in our cohort) as multifactorial etiology for renal insufficiency, this accounted for the leading cause of CKD with $48 \%$ of the patients ( $n=32)$. Regarding comorbidities, $26.8 \%$ of the patients where diabetic, $88 \%$ had hypertension and $32.8 \%$ presented with some extent of cardiovascular disease. Prior to enrolment 5 patients were treated with ketoanalogues supplements and diet. Thirty-five patients did not have prior nephrological care (late referral) and 32 had nephrological care and received erythropoiesis stimulator agents and secondary hyperparathyroidism treatment such as calcium and vitamin D supplements. We did not find statistical difference in frailty (3.0 \pm 1.3 vs 3.2 $\pm 1.3, P=0.48)$ and $\mathrm{CHI}(5.03 \pm 1.8$ versus. $5.52 \pm 2.1, P=$ 0.31 ) between patients according to prior nephrological care (Table 2).

The median estimated glomerular filtration rate (eGFR) at entry was $6.9(5-10) \mathrm{mL} / \mathrm{min} / 1.73 \mathrm{~m} 2$. The median value of hematocrit and serum albumin were 28\% (17-33\%) and $3.7 \mathrm{~g} / \mathrm{dL}(2.4-4.9 \mathrm{~g} / \mathrm{dL})$ respectively. HD accounted for the most common renal replacement modality with 62 patients (92\%) and transient catheters were the most common vascular access $n=37(55 \%)$. The median body mass index was $26 \mathrm{~kg} / \mathrm{m}^{2}\left(14.8-40 \mathrm{~kg} / \mathrm{m}^{2}\right)$. The median for $\mathrm{CHI}$ at enrolment was $5.2(2-10)$. We found a significant improvement in hematocrit and serum calcium at month six. Regarding treatment modalities, $29 \%$ of the patients $(\mathrm{n}=15)$ remained in HD and $71 \%$ changed to HDF during the study. In contrast with the data presented at enrolment at the end of the trial prothesis and native fistulas were the most common vascular access accounting for $86.5 \%$ of the patients while $13.5 \%$ had a permanent catheter. The median score of frailty at dialysis entry was of three $(2-4)$ versus one $(1-2)$ at month six $(P<0.0001)$. The prevalence of $\mathrm{F}$ at the beginning of the study accounted for $65.7 \%$ of the population, in contrast in the 52 patients who remained in the study until completion, the frailty prevalence descended to $19 \%$ with a corresponding increase to $81 \%$ of pre-frail patients $(P<0.0001)$.

No patient with involuntary weight loss was observed. The respective medians for each frail parameter at month six where: Walking speed 5.5 (3-9), grip strength 23 (10-50), exhaustion $0.3(0-3)$ and physical activity 1734 (197.6-7159) kcal/wk. Walking for leisure was the physical activity most commonly observed in the study.

After dividing the population into frail (FR) and pre-frail (PF) groups, we stratified age in three groups from 18 to $39 ; 40$ to 61 and 62 years or older and observed that patients in the last group had more prevalence of frailty $(P<0.0001)$. We did not find significant differences between genders. Median eGFR in the FR group $8.1 \mathrm{~mL} /$ min (1.5-17) was greater than in the PF group: $7.1 \mathrm{~mL} /$ min $(2-14)(P<0.0001)$. CHI median in the FR group was higher six $(2-10)$ than PF group: $2(4-7)(P<0.0001)$. Serum albumin levels were lower in FR group $(P<0.03)$. 


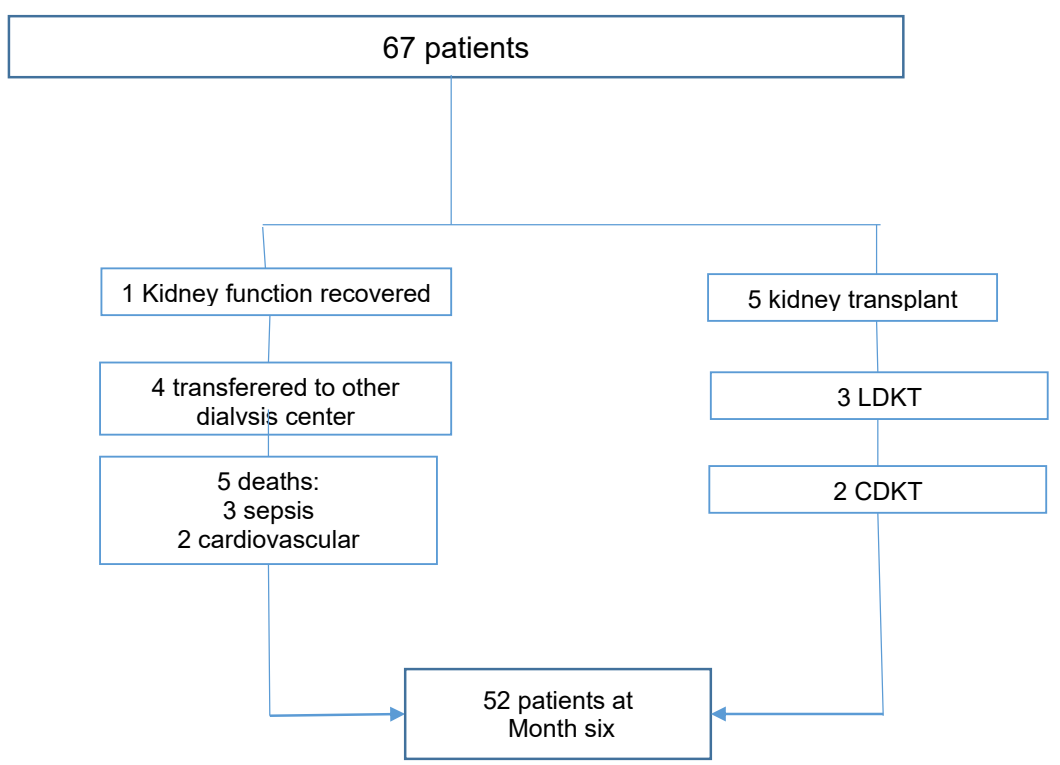

Figure 1. Follow up at six months. LDKT: living donor kidney transplant, CDKT: cadaveric donor kidney transplant.

We observed five (11.4\%) deaths in the FR group compared with no deaths in PF group $(P<0.01)$. Causes of death were cardiovascular $(n=2)$ and infectious $(n=3)$. The frail group also had a lesser number of kidney transplants $(P=0.02$; Tables 3 and 4$)$.

The frailty test had a significant statistical correlation with the CHI, $(\mathrm{r}=0.54 ; P<0.0001)$ suggesting that patients with greater number of comorbidities are more frailty (Figure 2). In the linear multivariate analysis, $\mathrm{CHI}(P<0.0001)$ and serum albumin $(P<0.003)$ were the only predictors of frailty (Table 5).

\section{Discussion}

In the present study, the prevalence of frailty in patient's incident in RRT was $67.5 \%$ using the Fried frail score by the physical method. This data is similar to the prevalence reported in Bao et al (73\%) counting with a population of 1576 patients who initiate dialysis from Comprehensive Dialysis Study (CDS) using the Fried Frail score criteria by the self-reported method (15). The prospective study by Bárbara et al including 95 patients on pre-dialysis, showed a prevalence of $\mathrm{F}$ for patients over 65 years of $44 \%$ using the Groningen Frailty Indicator (GFI) test, the Identification of Seniors at Risk-Hospitalized Patients (ISAR-HP) and the Veiligheids management system (VMS). This prevalence compared with the Fried Frail self-report test had lower sensitivity and specificity (GFI 89\% / 57\%, ISAR-HP 83\% / $77 \%$ and VMS 77\% / 67\% respectively) (16). Several studies report that the prevalence of $\mathrm{F}$ is modified according to the method used to measure it, as well as gender, age, and comorbidities. Leaving aside these variations, the Fried Frail test by the physical method has a high sensitivity and specificity compared to other techniques in the incident population on dialysis, especially in patients older than 40 years. Based on the above, we have chosen this method to evaluate our patients. A significant improvement in frailty status, hematocrit and calcemia was observed during the follow-up. We believe it was due to better medical control (monthly control), therapeutic compliance, improvement in nutritional status and physical state which we think accounts for the optimization of the internal environment and the elimination of blood toxins, hence we do not consider that this finding represents a selection biases. We also observed that frailty increases proportionally to age (group $40-61$ years, $18 \%$ and $>62$ years $82 \%$ ), as occurred in the cross-sectional study by Johansen et al with incidents in HD that are part of the longitudinal Dialysis Morbidity and Mortality Study (DMMS), where the prevalence in those under 40 years of age was $44.4 \%$, in those aged 60 to $70,74.2 \%$ and 80 or more $78.8 \%$ (12). The high prevalence of frailty in patients requiring dialysis compared to the healthy population over 50 years (7 to 17\%) according to cross-sectional CHS studies (Cardiovascular Health Study and SHARE STUDY (Study, Survey of Health, Aging and Retirement in Europe), is an important observation with potential clinical benefits its diagnosis and early prevention (1). The cohort of patients with a score for FR had a mortality of $11.4 \%$ compared to $0 \%$ in the pre-frail patients. It is reasonable to expect that mortality could increase with a longer period of observation, as demonstrated by the prospective study by McAdams-DeMarco et al in 146 HD patients in whom mortality was $40 \%$ at 3 years of follow-up, also associating a 3-fold higher risk of death independently compared to non-frailty patients in HD (RR: 2.6 ; 95\% CI: $1.04-$ $6.49, P=0.04)(17)$. In the present study, the F measured by the Fried Frail physical method test had a significant correlation with the age-adjusted $\mathrm{CHI}$ at the start of RRT ( $\mathrm{r}=0.54, P<0.0001)$. However, a retrospective study by Kim et al using the claim frailty index (CFI) test in 
Table 2. Characteristics at baseline and at month 6

\begin{tabular}{|c|c|c|c|}
\hline Variables & $\begin{array}{l}\text { Baseline } \\
\mathrm{n}=67(\%)\end{array}$ & $\begin{array}{l}\text { Month } 6 \\
\mathrm{n}=52(\%)\end{array}$ & $\boldsymbol{P}$ \\
\hline \multicolumn{4}{|l|}{ Demographics } \\
\hline Age & $64 \pm 17$ & & \\
\hline Male, n (\%) & $43(64)$ & & \\
\hline \multicolumn{4}{|l|}{ Causes of CKD } \\
\hline Glomerulonephritis & $9(13.4)$ & & \\
\hline Hypertension & $14(20.8)$ & & \\
\hline Multiple myeloma & $4(6)$ & & \\
\hline Multifactorial* & $32(48)$ & & \\
\hline Polycystic renal disease. & $5(7.4)$ & & \\
\hline Obstructive uropathy** & $3(4.4)$ & & \\
\hline \multicolumn{4}{|l|}{ Laboratory values } \\
\hline CKD-EPI, mL/min/1.73 m² & $6.9(5-10)$ & & \\
\hline Albumine, mg/dL & $3.7(2.4-4.9)$ & $3.9(3-7.9)$ & 0.2 \\
\hline Urea, mg/dL & $197(43-654)$ & $135(84.4-214)$ & 0.04 \\
\hline $\mathrm{PCR}, \mathrm{mg} / \mathrm{dL}$ & $1.1(0.2-3.4)$ & $5.3(0.1-33)$ & 0.01 \\
\hline Transferrin, ng/dL & $183.7(105-272)$ & $192(128-331)$ & 0.1 \\
\hline Transferrin saturation, $\%$ & $24.8(9-69)$ & $27.3(6-83)$ & 0.3 \\
\hline $25-\mathrm{OH}, \mathrm{mg} / \mathrm{dL}$ & $18(11.7-27.7)$ & Not measured & \\
\hline Calcium, mg/dL & $8.6(6.9-10.7)$ & $8.8(7.3-10)$ & $<0.002$ \\
\hline Phosphorus, mg/dL & $5.5(1.2-10.5)$ & $5.8(1.5-9.6)$ & 0.9 \\
\hline Hematocrit, \% & $28(17-33)$ & $32.7(19.3-44.8)$ & 0.05 \\
\hline \multicolumn{4}{|l|}{ Dialysis modality, n (\%) } \\
\hline Hemodialysis & $62(92)$ & $15(29)$ & $<0.001$ \\
\hline Online hemodiafiltration & $5(8)$ & $37(71)$ & \\
\hline \multicolumn{4}{|l|}{ Vascular access, n (\%) } \\
\hline Transient catheter & $37(55)$ & & \\
\hline Permanent catheter & $6(9)$ & $7(13.5)$ & $<0.01$ \\
\hline Prosthetic or native fistula & $24(36)$ & $45(86.5)$ & \\
\hline \multicolumn{4}{|l|}{ Other } \\
\hline $\mathrm{BMI}\left(\mathrm{kg} / \mathrm{m}^{2}\right)$ & $26(14.8-40)$ & & \\
\hline Charlson Index & $5.2(2-10)$ & & \\
\hline $\mathrm{Kt} / \mathrm{V}^{* * *}$ & & $1.5(0.9-2.2)$ & \\
\hline
\end{tabular}

* It was considered multifactorial with 2 or more comorbidities at the same time, except that the cause of CKD was evidenced by imaging methods, renal biopsy or bone marrow.

** Prostatic hypertrophy, there was no other related cause.

*** $\mathrm{Kt} / \mathrm{V}$ dialysis quality and efficacy measurement parameter $\mathrm{K}$ : urea clearance in dialysis process, $\mathrm{T}$ : dialysis time and $\mathrm{V}$ : urea distribution volume.

Table 3. Parameters of frailty at admission and sixth month

\begin{tabular}{llll}
\hline Frailty test & $\begin{array}{l}\text { Admission } \\
\mathbf{n = 6 7}\end{array}$ & $\begin{array}{l}\text { Sixth month } \\
\mathbf{n = 5 2}\end{array}$ & $\boldsymbol{P}$ \\
\hline Frailty (median) & $3(2-4)$ & $1(1-2)$ & $<0.0001$ \\
Frail, n (\%) & $44(65.7 \%)$ & $10(19 \%)$ & $<0.0001$ \\
Pre-frail, n (\%) & $23(34.3 \%)$ & $42(81 \%)$ & \\
\hline
\end{tabular}

3642 volunteer older adults with different comorbidities showed that this was significantly higher than the $\mathrm{CHI}$ to predict disability (0.62-0.72 viruses. $0.58-0.66, P \leq 0.01)$ and morbidity ( 0.58 viruses. $0.66, P \leq 0.01)$, not so to predict mortality ( 0.68 vs. $0.68 ; P=0.5)$ or hospitalization (0.58 vs. $0.54, P=0.07$ ) (14). In our study there was a decrease in the percentage of patients with $\mathrm{F}$ after sixth month of RRT (65.7 vs. 19\%), improvement in walking speed time (5.5 versus $6 \mathrm{~m} / \mathrm{s})$ and in the exhaustion $(0.3$ vs. 2.5 points), increased physical activity (1734 vs. 493 $\mathrm{kcal} / \mathrm{wk}$ ) and increased grip strength (23 versus $20 \mathrm{~kg}$ ). The vast majority of studies on $\mathrm{F}$ in dialysis patients evaluate this population with cross-sectional studies; however, a study by Lee et al showed similar data to our work (18). Forty-six incident patients older than 65 years undergoing $\mathrm{HD}$ were evaluated with a comprehensive geriatric assessment (CGA) frailty score, obtained a 32,6\% of frailty (defined as a CGA $>10$ ). This group observed that in the CGA index carried out in 29 (60.4\%) patients at 12 months they showed an improvement in the median score, being at baseline 8 versus 6 a year $(P<0.001)(18)$. To our knowledge, there is no literature on other studies showing the prevalence of $\mathrm{F}$ at the start of dialysis with a follow-up after 6 or 12 months. We find important to state the idea that the manifestations of the uremic syndrome can overlap with the frailty syndrome, sharing several of its symptoms, such as exhaustion, weight loss and decrease in muscle mass. This could support the fact that in the first months a significant improvement is evident in the initiation of RRT patients with uremic symptoms. This would not be the case in frail patients for whom RRT may worsen, improve slowly or maintain their symptoms (19). That is why, in view of the false positives that can occur for the diagnosis of $\mathrm{F}$ at the beginning of RRT, we consider necessary to evaluate more diagnostic tools of greater specificity and, in the same way highlight the need of prospective studies with longer times.

\begin{tabular}{lccc}
\multicolumn{4}{l}{ Table 4. Variables in frail and Pre-frail groups } \\
\hline Variable & $\begin{array}{c}\text { Frail } \\
\mathbf{n}=\mathbf{4 4}\end{array}$ & $\begin{array}{c}\text { Pre-Frail } \\
\mathbf{n = 2 3}\end{array}$ & $\boldsymbol{P}$ \\
\hline Age & $74(40-91)$ & $48(18-77)$ & $<0.001$ \\
Groups by age & 0 & $7(30.5 \%)$ & \\
$18-39$ & $8(18 \%)$ & $11(47.8 \%)$ & $<0.0001$ \\
$40-61$ & $36(82 \%)$ & $5(21.7 \%)$ & \\
$>62$ & $28(63.6 \%)$ & $15(65.2 \%)$ & 0.36 \\
Male gender & $8.1(1.5-17)$ & $7.1(2-14)$ & $<0.0001$ \\
eGFR, mL/min & $6(2-10)$ & $2(4-7)$ & $<0.0001$ \\
Charlson Index & $3.6(2.4-4.5)$ & $4(2.8-4.9)$ & 0.03 \\
Albumin & 1.15 & 2.7 & 0.05 \\
PCR & 0 & 5 & 0.02 \\
Kidney transplant & 5 & 0 & 0.01 \\
\hline Deaths & & & \\
\hline
\end{tabular}


Table 5. Multivariate linear regression (Dependent variable: fragility)

\begin{tabular}{lcccc}
\hline Variable & OR & $\boldsymbol{P}$ & \multicolumn{2}{c}{$\mathbf{9 5 \%} \mathbf{C l}$} \\
\hline Sex & 0.70 & 0.472 & 3.62 & 2.72 \\
Charlson Index & 0.479 & $<0.0001$ & 0.19 & 0.45 \\
Albumin & -0.319 & $<0.003$ & -1.47 & -0.32 \\
CKD-EPI & 0.117 & 0.309 & -0.44 & 0.13 \\
Calcium & 0.345 & 0.520 & 0.25 & 1.22 \\
Phosphorus & -0.92 & 0.440 & -0.26 & 0.11 \\
Urea & 0.47 & 0.701 & -0.003 & 0.005 \\
\hline
\end{tabular}

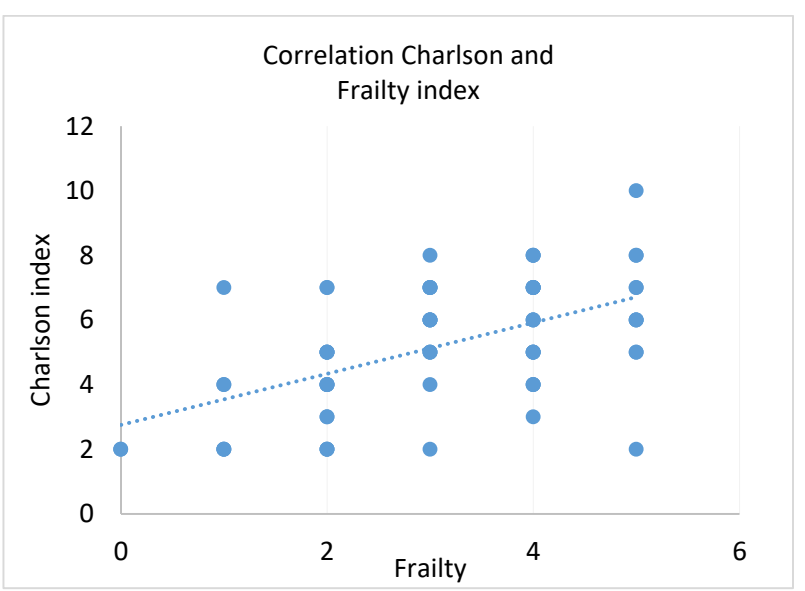

Figure 2. Correlation histogram between Frailty Index and Charlson ( $r=0.54$, $P<0.0001)$.

\section{Conclusion}

The prevalence of frailty in patient's incident starting two different dialysis modalities was $67.5 \%$. There was an improvement in frailty test after six months of dialysis. Mortality in patients with frailty was related with lower levels of albumin and an increased CHI.

\section{Limitations of the study}

The main limitation of this study is the number of patients at the beginning of the trial, which was not sufficiently representative for extracting conclusive results. The follow up period was only of six months, which limits the observations on the long-term behavior of frailty. It may be argued that the loss of $22 \%$ of data $(n=15)$ may affect this study validity, but we think that the results would not be much different with lesser loss of data. Nevertheless, the strength of this study resides in the follow up and reevaluation of the majority of patients after six months of having initiated a dialysis therapy

Availability of data and materials

The datasets generated and/or analyzed during the current study are not publicly available due was generate by the authors in an excel program, but are available from the corresponding author on reasonable request.
Authors' contribution

SS created and recollected the data of all participants, wrote the manuscript. CM, AA and CD reviewed some results. GG translated to English. GL and SS analyzed the statistics data.

\section{Conflicts of interest}

The authors declare that they have no competing interests.

\section{Ethical considerations}

Ethical issues (including plagiarism, data fabrication, double publication) have been completely observed by the authors.

\section{Funding/Support}

We want to confirm that this study was an investigator initiated studies (IIS) and did not received any research funding.

\section{References}

1. García-García FJ, Larrión Zugasti JL, Rodríguez Mañas L. Fragilidad: un fenotipo en revisión [Frailty: a phenotype under review]. Gac Sanit. 2011;25 Suppl 2:51-8. Spanish. doi: 10.1016/j.gaceta.2011.08.001.

2. Musso CG, Jauregui JR, Macías Núñez JF. Frailty phenotype and chronic kidney disease: a review of the literature. Int Urol Nephrol. 2015;47:1801-7. doi: 10.1007/s11255-015-1112-z.

3. Johansen KL, Dalrymple LS, Glidden D, Delgado C, Kaysen GA, Grimes B, et al. Association of Performance-Based and Self-Reported Function-Based Definitions of Frailty with Mortality among Patients Receiving Hemodialysis. Clin J Am Soc Nephrol. 2016;11:626-32. doi: 10.2215/CJN.03710415.

4. Johansen KL, Dalrymple LS, Delgado C, Kaysen GA, Kornak J, Grimes B, et al. Comparison of self-report-based and physical performance-based frailty definitions among patients receiving maintenance hemodialysis. Am J Kidney Dis. 2014;64:600-7. doi: 10.1053/j.ajkd.2014.03.016.

5. Fried LP, Tangen CM, Walston J, Newman AB, Hirsch C, Gottdiener J, et al. Cardiovascular Health Study Collaborative Research Group. Frailty in older adults: evidence for a phenotype. J Gerontol A Biol Sci Med Sci. 2001;56(3):M14656. doi: 10.1093/gerona/56.3.m146

6. Gruenewald TL, Seeman TE, Karlamangla AS, Sarkisian CA. Allostatic load and frailty in older adults. J Am Geriatr Soc. 2009;57(9):1525-31. doi: 10.1111/j.15325415.2009.02389.x.

7. Puts MT, Visser M, Twisk JW, Deeg DJ, Lips P. Endocrine and inflammatory markers as predictors of frailty. Clin Endocrinol (Oxf). 2005;63(4):403-11. doi: 10.1111/j.13652265.2005.02355.x.

8. Hyde Z, Flicker L, Almeida OP, Hankey GJ, McCaul KA, Chubb SA, et al. Low free testosterone predicts frailty in older men: the health in men study. J Clin Endocrinol Metab. 2010; 95(7):3165-72. doi: 10.1210/jc.2009-2754.

9. Roubenoff R, Parise H, Payette HA, Abad LW, D'Agostino $\mathrm{R}$, Jacques PF, et al. Cytokines, insulin-like growth factor 1 , sarcopenia, and mortality in very old community-dwelling men and women: the Framingham Heart Study. Am J Med. 2003;115(6):429-35. doi: 10.1016/j.amjmed.2003.05.001.

10. Woods NF, LaCroix AZ, Gray SL, Aragaki A, Cochrane BB, Brunner RL, et al. Women's Health Initiative. Frailty: emergence and consequences in women aged 65 and older in the Women's Health Initiative Observational Study. J Am Geriatr Soc. 2005;53:1321-30. doi: 10.1111/j.1532-5415.2005.53405.x. Erratum in: J Am Geriatr Soc. 2017;65:1631-1632.

11. Roshanravan B, Khatri M, Robinson-Cohen C, Levin G, Patel $\mathrm{KV}$, et al. A prospective study of frailty in nephrology-referred patients with CKD. Am J Kidney Dis. 2012;60:912-21. doi: 10.1053/j.ajkd.2012.05.017 . 
12. Johansen KL, Chertow GM, Jin C, Kutner NG. Significance of frailty among dialysis patients. J Am Soc Nephrol. 2007;18:2960-7. doi: 10.1681/ASN.2007020221.

13. Nixon AC, Bampouras TM, Pendleton N, Woywodt A, Mitra $S$, Dhaygude A. Frailty and chronic kidney disease: current evidence and continuing uncertainties. Clin Kidney J. 2018;11:236-245. doi: 10.1093/ckj/sfx134.

14. Kim DH, Glynn RJ, Avorn J, Lipsitz LA, Rockwood K, Pawar A, et al. Validation of a Claims-Based Frailty Index Against Physical Performance and Adverse Health Outcomes in the Health and Retirement Study. J Gerontol A Biol Sci Med Sci. 2019;74:1271-1276. doi: 10.1093/gerona/gly197.

15. Bao Y, Dalrymple L, Chertow GM, Kaysen GA, Johansen KL. Frailty, dialysis initiation, and mortality in end-stage renal disease. Arch Intern Med. 2012;172:1071-7. doi: 10.1001/ archinternmed.2012.3020.
16. van Munster BC, Drost D, Kalf A, Vogtlander NP. Discriminative value of frailty screening instruments in end-stage renal disease. Clin Kidney J. 2016;9:606-10. doi: 10.1093/ckj/sfw061.

17. McAdams-DeMarco MA, Law A, Salter ML, Boyarsky B, Gimenez L, Jaar BG, et al. Frailty as a novel predictor of mortality and hospitalization in individuals of all ages undergoing hemodialysis. J Am Geriatr Soc. 2013;61:896-901. doi: 10.1111 /jgs.12266.

18. 18.Lee SW, Lee A, Yu MY, Kim SW, Kim KI, Na KY, et al. Is frailty a modifiable risk factor of future adverse outcomes in elderly patients with incident end-stage renal disease? J Korean Med Sci. 2017;32:1800-6. doi: 10.3346/jkms.2017.32.11.1800.

19. Johansen KL, Delgado C, Bao Y, Kurella Tamura M. Frailty and dialysis initiation. Semin Dial. 2013;26:690-6. doi: 10.1111/ sdi.12126. 